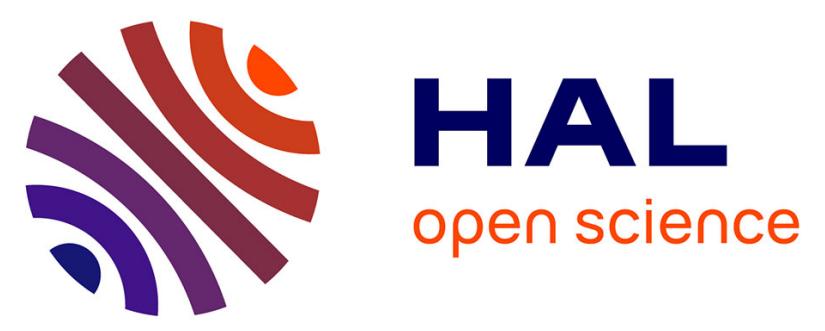

\title{
Influence of Venus topography on the zonal wind and UV albedo at cloud top level: The role of stationary gravity waves.
}

Jean-Loup Bertaux, Igor V. Khatunstsev, Alain Hauchecorne, Wojciech J. Markiewicz, Emmanuel Marcq, Sébastien Lebonnois, Marina Patsaeva, Alexander Turin, Anna Fedorova

\section{To cite this version:}

Jean-Loup Bertaux, Igor V. Khatunstsev, Alain Hauchecorne, Wojciech J. Markiewicz, Emmanuel Marcq, et al.. Influence of Venus topography on the zonal wind and UV albedo at cloud top level: The role of stationary gravity waves.. Journal of Geophysical Research. Planets, 2016, 121 (6), pp.1087-1101. 10.1002/2015JE004958 . insu-01328045

\section{HAL Id: insu-01328045 https://hal-insu.archives-ouvertes.fr/insu-01328045}

Submitted on 19 Jul 2016

HAL is a multi-disciplinary open access archive for the deposit and dissemination of scientific research documents, whether they are published or not. The documents may come from teaching and research institutions in France or abroad, or from public or private research centers.
L'archive ouverte pluridisciplinaire HAL, est destinée au dépôt et à la diffusion de documents scientifiques de niveau recherche, publiés ou non, émanant des établissements d'enseignement et de recherche français ou étrangers, des laboratoires publics ou privés. 


\section{Journal of Geophysical Research: Planets}

\section{RESEARCH ARTICLE}

10.1002/2015JE004958

Key Points:

- At equator the Venus zonal wind at cloud top level is discovered to vary with geographic longitude

- Stationary gravity waves generated by winds on orography at ground may decelerate the winds higher

- The UV albedo geographic map is anticorrelated to $\mathrm{H}_{2} \mathrm{O}$ map suggesting upwelling of UV absorber

Correspondence to:

J.-L. Bertaux,

jean-loup.bertaux@latmos.ipsl.fr

\section{Citation:}

Bertaux, J.-L., I. V. Khatuntsev,

A. Hauchecorne, W. J. Markiewicz,

E. Marcq, S. Lebonnois, M. Patsaeva,

A. Turin, and A. Fedorova (2016),

Influence of Venus topography on the

zonal wind and UV albedo at cloud top

level: The role of stationary gravity

waves, J. Geophys. Res. Planets, 121,

doi:10.1002/2015JE004958.

Received 16 OCT 2015

Accepted 17 MAY 2016

Accepted article online 6 JUN 2016

\section{Influence of Venus topography on the zonal wind and UV albedo at cloud top level: The role of stationary gravity waves}

\author{
Jean-Loup Bertaux' ${ }^{1}$, I. V. Khatuntsev ${ }^{2}$, A. Hauchecorne' ${ }^{1}$, W. J. Markiewicz ${ }^{3}$, E. Marcq ${ }^{1}$, S. Lebonnois ${ }^{4}$, \\ M. Patsaeva ${ }^{2}$, A. Turin ${ }^{2}$, and A. Fedorova ${ }^{2}$ \\ ${ }^{1}$ LATMOS/INSU/CNRS, UVSQ, Guyancourt, France, ${ }^{2}$ Space Research Institute, RAS, Moscow, Russia, ${ }^{3}$ Max Planck Institute for Solar \\ System Research, Göttingen, Germany, ${ }^{4}$ Laboratoire de Météorologie Dynamique, UMR 8539, IPSL, UPMC, CNRS, Paris, France
}

\begin{abstract}
Based on the analysis of UV images (at $365 \mathrm{~nm}$ ) of Venus cloud top (altitude $67 \pm 2 \mathrm{~km}$ ) collected with Venus Monitoring Camera on board Venus Express (VEX), it is found that the zonal wind speed south of the equator (from $5^{\circ} \mathrm{S}$ to $15^{\circ} \mathrm{S}$ ) shows a conspicuous variation (from -101 to $-83 \mathrm{~m} / \mathrm{s}$ ) with geographic longitude of Venus, correlated with the underlying relief of Aphrodite Terra. We interpret this pattern as the result of stationary gravity waves produced at ground level by the uplift of air when the horizontal wind encounters a mountain slope. These waves can propagate up to the cloud top level, break there, and transfer their momentum to the zonal flow. Such upward propagation of gravity waves and influence on the wind speed vertical profile was shown to play an important role in the middle atmosphere of the Earth by Lindzen (1981) but is not reproduced in the current GCM of Venus atmosphere from LMD. (Laboratoire de Météorologie Dynamique)

In the equatorial regions, the UV albedo at $365 \mathrm{~nm}$ varies also with longitude. We argue that this variation may be simply explained by the divergence of the horizontal wind field. In the longitude region (from $60^{\circ}$ to $-10^{\circ}$ ) where the horizontal wind speed is increasing in magnitude (stretch), it triggers air upwelling which brings the UV absorber at cloud top level and decreases the albedo and vice versa when the wind is decreasing in magnitude (compression). This picture is fully consistent with the classical view of Venus meridional circulation, with upwelling at equator revealed by horizontal air motions away from equator: the longitude effect is only an additional but important modulation of this effect. This interpretation is comforted by a recent map of cloud top $\mathrm{H}_{2} \mathrm{O}$, showing that near the equator the lower UV albedo longitude region is correlated with increased $\mathrm{H}_{2} \mathrm{O}$. We argue that $\mathrm{H}_{2} \mathrm{O}$ enhancement is the sign of upwelling, suggesting that the UV absorber is also brought to cloud top by upwelling.
\end{abstract}

\section{Introduction}

Venus is enshrouded in a veil of thick clouds composed of $\mathrm{H}_{2} \mathrm{SO}_{4}-\mathrm{H}_{2} \mathrm{O}$ liquid droplets. The presence of a (still unidentified) UV absorber at cloud top level manifests itself with UV markings, which allowed determining that the atmosphere was rotating in a retrograde fashion with a period of $\sim 4$ days [Boyer and Camichel, $1961]$, corresponding to a westward zonal wind of $\sim 100 \mathrm{~m} / \mathrm{s}$. Radar observations later revealed that the solid body was also rotating in a retrograde direction but at a much slower rate (period 243.02 days or $1.81 \mathrm{~m} / \mathrm{s}$ ). The reason of this atmospheric superrotation is still debated. Other radar/altimeter observations from space missions revealed also a number of topographic features (mountains/volcanoes). Zonal wind measurements (from tracking of UV cloud features) were obtained from several space missions including Venus Express Venus Monitoring Camera (VMC) [Rossow et al., 1990; Khatuntsev et al., 2013]. VMC/Venus Express (VEX) camera has confirmed the previous findings that the zonal wind speed depended on latitude and local time. Here we show for the first time that one major parameter modulating the zonal wind is the ground-level topography several thousands of kilometers upstream of the observed wind (deceleration up to $17 \mathrm{~m} / \mathrm{s}$ ), a fact that had escaped notice before. As an explanation, we propose a mechanism based on gravity waves produced by the topography, propagating upward up to the convective zone just below the cloud top level where they break and communicate their momentum to the atmosphere.

Section 2 presents the zonal wind measurements with VMC/VEX with two representations: one as a function of longitude for a constant latitude just below the equator and also a longitude-latitude (geographic) map, both compared to topography. In section 3 is described our proposed mechanism of stationary gravity waves generated at ground level and propagating upward to the cloud top level where they decelerate the zonal 


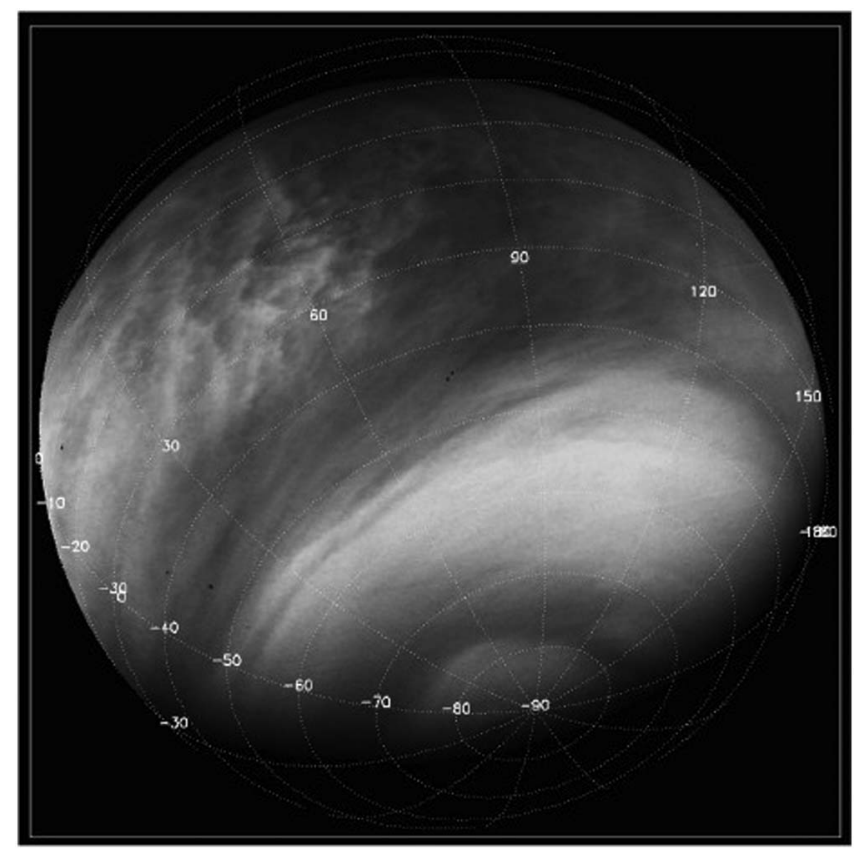

Figure 1. An example of VMC image (UV, $365 \mathrm{~nm}$ ) taken from a distance of around $33,000 \mathrm{~km}$ ( $\sim 3 \mathrm{~h}$ before pericenter) on the dayside. This is UV image \#0030 of orbit \#0462 obtained on 27 July 2007. The latitudelongitude grid is indicated. Cloud markings are used to determine winds at cloud top level. The superrotation is from right to left. wind. In section 4 we discuss some previous observations of gravity waves and the trajectories of the two VEGA balloons flown in 1985 at $53 \mathrm{~km}$ of altitude. Section 5 is devoted to UV albedo mapping and comparison to $\mathrm{H}_{2} \mathrm{O}$ mapping, with conclusions in section 6 and three complementary appendices.

\section{Zonal Wind Measurements With VMC/VEX and Comparison With Topography}

The Venus Monitoring Camera (VMC) took simultaneous images in four narrowband channels $(365,513,950$, and $1010 \mathrm{~nm}$ ) projected on one CCD detector [Markiewicz et al., 2007a, 2007b; Titov et al., 2012]. Here we used only the UV images at $365 \mathrm{~nm}$ taken on the dayside, showing the highest contrast thanks to a still unidentified UV absorber near cloud top altitude. As discussed in Del Genio and Rossow [1990], the altitude of cloud top level is at $70 \mathrm{~km}$ ( 30 mbar) in low and middle latitudes relevant to the present work. The UV markings are slightly lower than the estimated cloud top but above $65 \mathrm{~km}$ ( 100 mbar). In the following we will refer for simplicity to wind at cloud top, though the UV markings are actually in the altitude range $67 \pm 2 \mathrm{~km}$. Each image (Figure 1) displays a wealth of UV markings. The change of position of a particular UV cloud feature between two images of the same region can be translated into a horizontal wind measurement [Moissl et al., 2009; Khatuntsev et al., 2013; Patsaeva et al., 2015]. The time separating two images of a pair examined for wind tracking varied from 20 to $60 \mathrm{~min}$, depending on the distance of VEX to the planet.

Because of the particular VEX orbit configuration, all latitudes were not covered equally with cloud tracking wind measurements. Venus Express orbit was very eccentric, $24 \mathrm{~h}$ period, pericenter at $200-400 \mathrm{~km}$ near the North Pole and apocenter at $66,000 \mathrm{~km}$ facing the South Pole. This orbit allowed VMC to acquire global views of the Venus southern hemisphere when the spacecraft was at apocenter. A portion of the orbit favorable for wind measurements was when VEX was moving from a distance of $66,000 \mathrm{~km}$ down to a distance of $12,000 \mathrm{~km}$ from the planet. As a result, wind measurements were obtained mainly in the southern hemisphere. Both manual $(45,600)$ and digital $(391,600)$ individual measurements over 127 orbits were analyzed covering from 2006 to 2012 [Khatuntsev et al., 2013].

In low-latitude regions $\left(5^{\circ} \mathrm{S}\right.$ to $25^{\circ} \mathrm{S}$ ) the velocities of zonal winds are found in the range $\sim 80$ to $120 \mathrm{~m} / \mathrm{s}$ (retrograde; therefore, negative in the geographic system longitude-latitude), while the velocity of meridional winds slowly increases from 0 at equator to about $10 \mathrm{~m} / \mathrm{s}$ poleward at $50^{\circ} \mathrm{S}$ latitude and then decreases to 0 at the pole [Khatuntsev et al., 2013]. A minimum in the zonal speed was found close to the noon (11-14 h local time LT) and maxima in the morning (8-9 h LT) and in the evening (16-17 h LT) [Khatuntsev et al., 2013]. In their paper, a Lomb-Scargle period analysis of the time series of measurements (a periodogram) showed a peak period at 117 days that triggered our attention. The peak is larger than the $99.99 \%$ confidence limit. Indeed, 117 days is the length of the Venus solar day, the time required for a particular geographic point (for example, a mountain) to be illuminated by the Sun. As discussed in section A1, if measurements of one parameter are requiring solar light, and if this parameter is linked to geography, a peak at 117 days is expected in the periodogram of the measurements. Reciprocally, when a peak at 117 days is present, one might expect a correlation with the geography. 


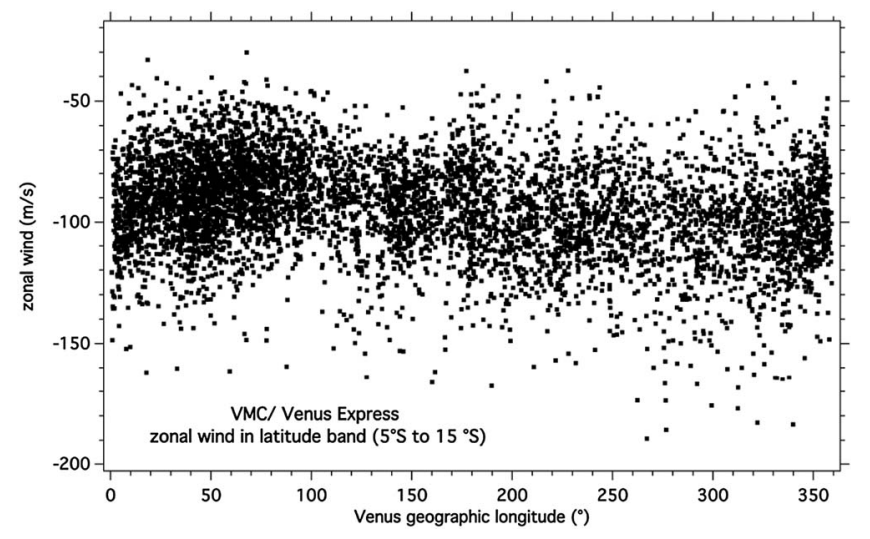

Figure 2. All zonal wind measurements performed manually over 127 orbits in the latitude range from $5^{\circ} \mathrm{S}$ to $15^{\circ} \mathrm{S}$ latitude are plotted as a function of Venus geographic longitude.
The present study is based on a data set collected over 127 orbits of Venus Express by VMC (Venus Monitoring Camera) instrument in the period from 2006 to 2012. It contains 31,604 zonal wind measurements performed manually by cloud tracking of UV features on VMC/Nenus Express images in the latitude range from $5^{\circ} \mathrm{S}$ to $45^{\circ} \mathrm{S}$, favored by the orbit configuration. The 6,312 measurements obtained in the latitude range from $5^{\circ} \mathrm{S}$ to $15^{\circ} \mathrm{S}$ are plotted as a function of Venus geographic longitude in Figure 2. At any longitude, there is a dispersion of points due to a combination of measurement error $(7$ to $30 \mathrm{~m} / \mathrm{s})$, natural variability, and other factors, like local time variation and waves [Khatuntsev et al., 2013].

The data in Figure 2 were smoothed by using a $10^{\circ}$ running window. In each window (centered every degree of longitude), the median value was kept (to avoid the effect of outliers) and plotted as a function of geographic longitude in Figure 3. There is a very clear longitude signature. While the average zonal wind in the longitude range $200-330^{\circ}$ is $-100.9 \mathrm{~m} / \mathrm{s}$, it reaches $-83.4 \mathrm{~m} / \mathrm{s}$ in the range $60-100^{\circ}$, a difference of $17.5 \mathrm{~m} / \mathrm{s}$. The blue curve in Figure 3 is the average altitude obtained by averaging the altimetry in the latitude band from $5^{\circ} \mathrm{S}$ to $15^{\circ} \mathrm{S}$ for each degree in longitude. The wind speed observed at cloud top level seems correlated to the relief altitude several tens of kilometers below, with some downstream shift, according to the wind direction indicated by the arrow.

The zonal wind curve of Figure 3 and the relief altitude curve are again plotted together in Figure 4, but this time the zonal wind curve is shifted to the east (upstream) by $30^{\circ}$ with respect to its original position in Figure 3 . With such a shift, there is a striking similarity of both wind speed and relief altitude. This demonstrates that the zonal wind is decelerated downstream of the mountains in this latitude range from $5^{\circ} \mathrm{S}$ to $15^{\circ} \mathrm{S}$, though there is an altitude difference of about $60-70 \mathrm{~km}$ between the ground and the cloud top level. The similarity of the curves is obvious for the main mountains around $80-140^{\circ}$ longitude but seems to exist

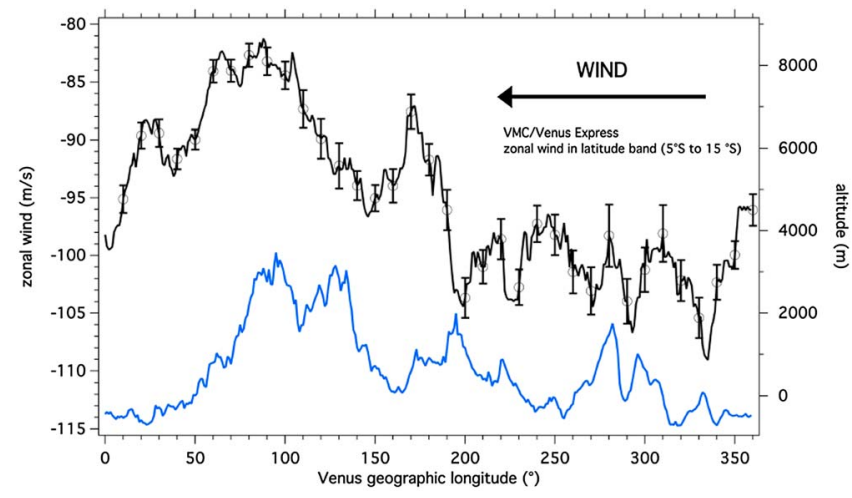

Figure 3. Black curve, left scale: median zonal wind in each bin of $10^{\circ}$ longitude, in the latitude band from $5^{\circ} \mathrm{S}$ to $15^{\circ} \mathrm{S}$. The dispersion of all points in a bin (standard deviation $\sigma$ ) is about $15-21 \mathrm{~m} / \mathrm{s}$. Every $10^{\circ}$ is marked an error $\operatorname{bar}(0.9-2.3 \mathrm{~m} / \mathrm{s})$, computed from $\sigma / \sqrt{n}$, where $n$ is the number of points in each bin. Therefore, all error bars are from independent measurements. Other schemes of binning (the mean instead of the median or the mean after elimination of points at more than $2 \sigma$ from the mean) give very similar curves. Blue curve, right scale: longitude distribution of the relief altitude averaged in the same latitude band from $5^{\circ} \mathrm{S}$ to $15^{\circ} \mathrm{S}$. also for smaller mountains, such as around $-160^{\circ}$ longitude. The optimal value of $30^{\circ}$ for the shift was obtained by correlating the wind curve with the relief curve with a variable longitude lag. The correlation coefficient as a function of the lag is shown in Figure 5. A maximum of 0.805 is obtained for a lag of about $30^{\circ}$.

In the following we compare a longitude-latitude map of Venus topography (from $5^{\circ} \mathrm{S}$ to $45^{\circ} \mathrm{S}$, Figure 6 , top) to a map of the zonal wind in the same latitude range (Figure 6, bottom), well covered by VMC and containing conspicuous mountains named Aphrodite Terra and Atla Regio. The zonal wind map shows a region of greatly decreased zonal wind, a feature that was totally unexpected and escaped attention up to now. In addition, the comparison of 


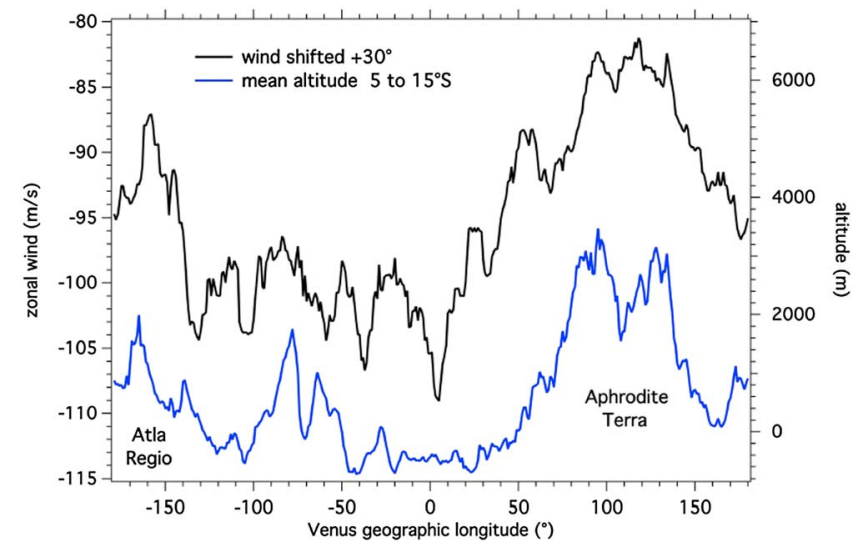

Figure 4. Longitude distributions of the relief altitude and of the zonal wind in the latitude-selected region (from $5^{\circ} \mathrm{S}$ to $15^{\circ} \mathrm{S}$ ). Blue curve: altitude in meters, left scale. Black curve: zonal wind $(\mathrm{m} / \mathrm{s})$, right scale. The longitude for the zonal wind was shifted by $+30^{\circ}$ from the original longitude plotted in Figure 3 to emphasize the correlation between the zonal wind and the relief. The longitude scale is now centered on $0^{\circ}$, from $-180^{\circ}$ to $180^{\circ}$ instead of 0 to $360^{\circ}$ of Figures 2 and 3. the two maps shows an obvious correlation of both maps (topography and wind speed), with the region of minimum wind (absolute speed) being displaced by $\sim 30^{\circ}$ downstream of the elevated highlands. The minimum zonal wind at $-82 \mathrm{~m} / \mathrm{s}$ (in absolute value) is found $30^{\circ}$ downstream of Aphrodite Terra, a highaltitude region ( $3000 \mathrm{~m}$ ) extending from $40^{\circ}$ to $160^{\circ}$ in longitude.

Therefore, we may conclude that there must be a mechanism triggered by the relief which decelerates significantly the mean zonal wind (observed $\sim 65 \mathrm{~km}$ above) about $30^{\circ}$ downstream of both Aphrodite Terra and Atla region highlands $(\sim 3200 \mathrm{~km}$ at equator). We propose that as illustrated in Figure 7, stationary gravity waves are generated by the horizontal wind flowing over a relief; then they propagate upward up to the altitude where they break and transfer their momentum to the general circulation. It is indeed a well-known fact that when gravity waves break, they transfer their momentum flux to the mean flow and they accelerate the zonal wind in the direction of their horizontal propagation relative to the mean flow [Lindzen, 1981]. For stationary waves on Venus this will result in a deceleration of the zonal flow, since the wind is increasing with altitude in the atmosphere of Venus (Figure 9, left).

On the wind map, the region of strong deceleration (red and yellow) seems to extend toward south, down to $-35^{\circ} \mathrm{S}$. This extension may be due to the south extension of the high terrains south of Aphrodite Terra. It might be also due to the fact that the slopes of the mountains at ground level are not all purely oriented east-west, facing east; their face may be oriented kinked to the north or to the south, and some trains of stationary waves might be generated with an oblique direction with respect to the longitudinal east-west axis. We could then expect also some propagation to the north. Unfortunately, wind measurements north of the limit of $-5^{\circ} \mathrm{S}$ are difficult with VMC because of the fast latitude motion in the northern hemisphere, as mentioned before.

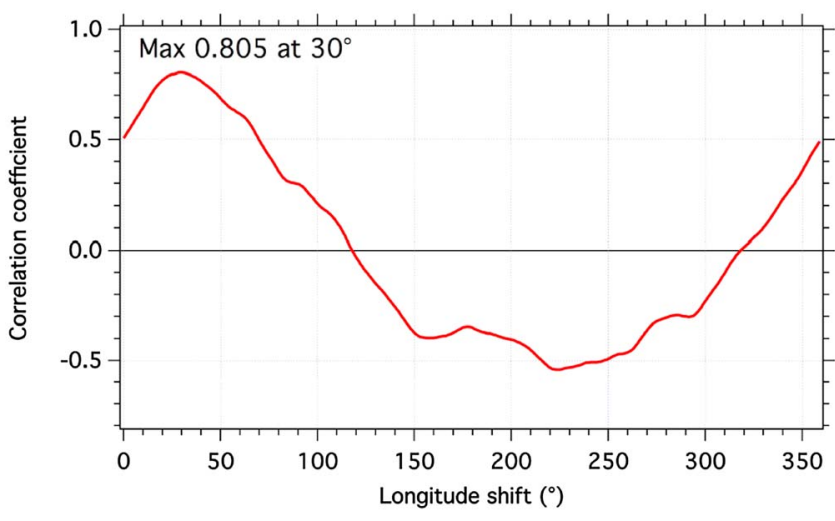

Figure 5. The correlation coefficient between the two curves (zonal wind and relief altitude displayed of Figure 3 ) is computed as a function of the longitude lag between the two curves. The maximum of correlation is 0.805 , obtained for a shift of the zonal wind curve by $30^{\circ}$ eastward.

\section{Deceleration of the Wind From Stationary Gravity Waves Breaking}

We discuss now some conditions for the deceleration mechanism associated to gravity waves (GW), which are wave disturbances where buoyancy is the restoring force. They can propagate vertically only in a stable atmosphere and can be triggered by a horizontal flow passing an obstacle or by convection below. In this case, we discuss the former orographic mechanism.

The static stability of the atmosphere is defined as stability $S=\mathrm{d} T / \mathrm{d} z-\Gamma$, where $T$ is the temperature, $z$ is altitude, and $\Gamma$ is adiabatic lapse rate. Figure 8 shows 

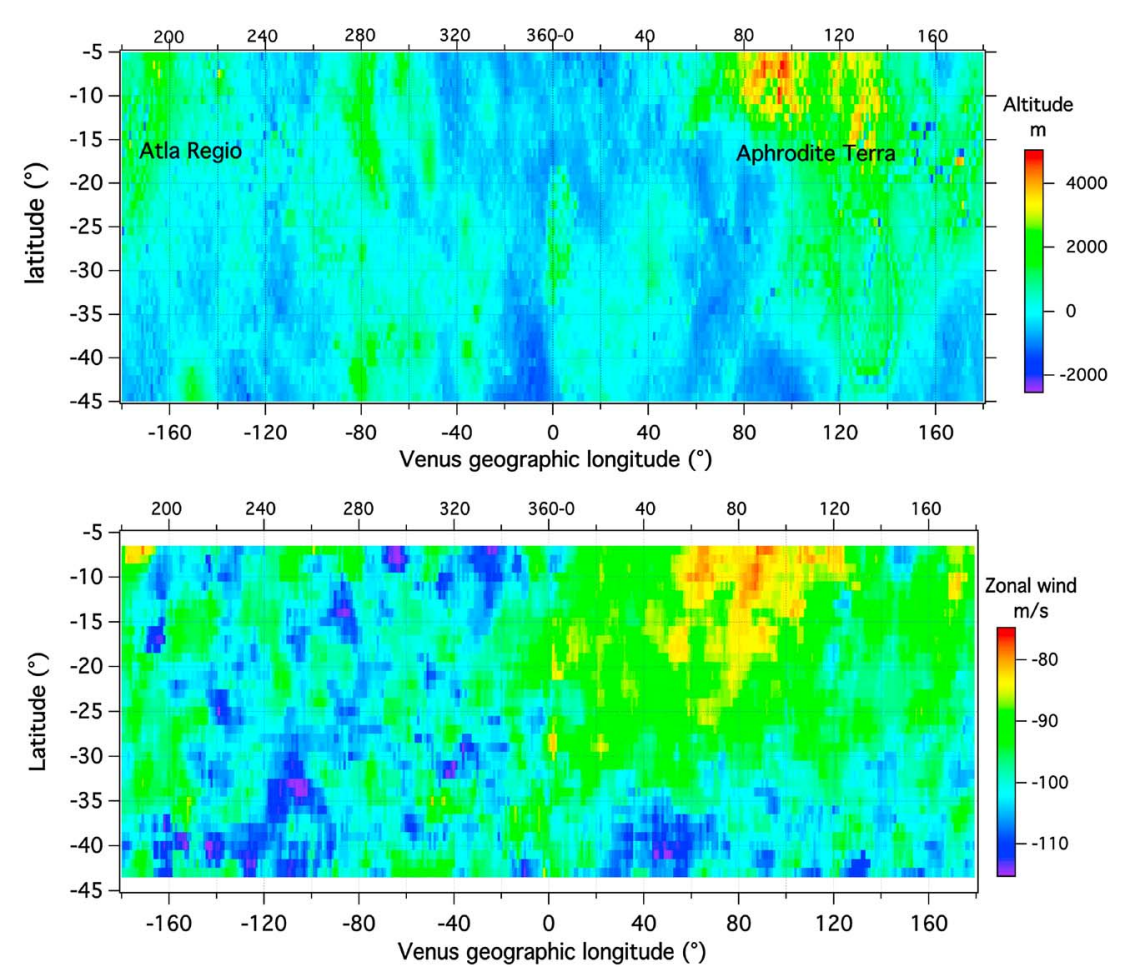

Figure 6. (top) Partial topographic map of Venus. Altitude is color coded. The latitude coverage of the map is limited from $5^{\circ} \mathrm{S}$ to $45^{\circ} \mathrm{S}$ to match the map of zonal wind. The zonal wind is oriented from right to left, from east to west, toward decreasing longitudes. Maps are centered on $0^{\circ}$ longitude. The scale 0 to $360^{\circ}$ longitude is indicated on top axis. The names of the highlands are written south of the reliefs. (bottom) Map of the zonal wind speed is in $\mathrm{m} / \mathrm{s}$ (color coded). There is a region of strong minimum (in absolute value) which is located $\sim 30^{\circ}$ downstream of the Aphrodite Terra highlands of Figure 6 (top); this region extends farther south in latitude. The wind map was obtained from a set of 31,604 manual measurements; a median filter was used in a box of $4 \times 4^{\circ}$ (longitude-latitude) around each point of the map to avoid outliers.

some vertical profiles of static stability obtained from in situ measurements (left) and Venus Express Radio Science Experiment (VeRa) radio occultations measurements on Venus Express [Tellmann et al., 2009] (right). In principle GW cannot propagate upward through a region of zero stability (convective zone). Pioneer Venus descending probes found $S$ to be $>0$ (with weak values in the $51-55 \mathrm{~km}$ convective zone); temperature

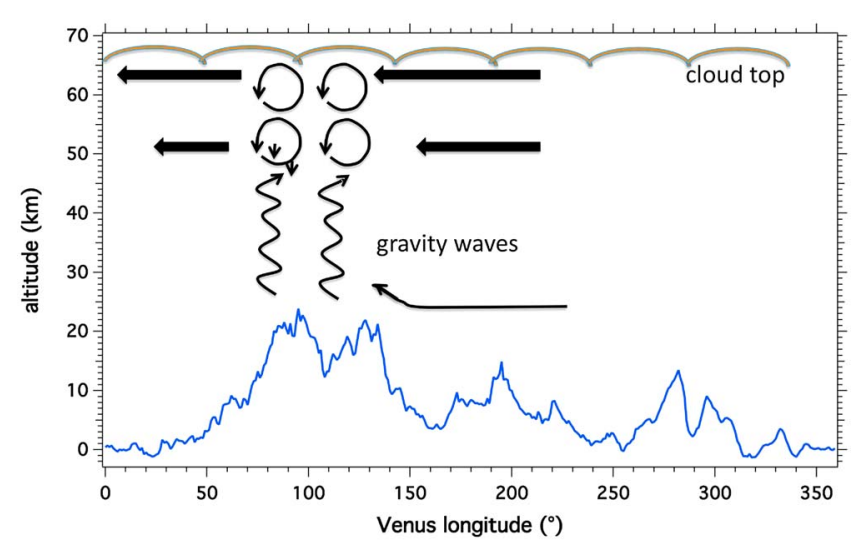

Figure 7. Sketch of gravity waves generated by interaction of the zonal wind on the mountains, propagating upward, breaking in the altitude region $50-60 \mathrm{~km}$, and decelerating the zonal wind at this altitude and higher. The altitude of the relief is exaggerated by a factor of 7 for better clarity. was not acquired below $12 \mathrm{~km}$. The VEGA-2 descent probe measured $S>0$ from 15 to $5 \mathrm{~km}$ (Figure 8, left) and $<0$ below $5 \mathrm{~km}$. Note also the difference in the region $55-58 \mathrm{~km}$ : low stability for VeRa/Venus Express (but still positive and larger than at other latitudes in the same altitude range) and high stability for Pioneer Venus and VEGA-2. Therefore, we may conclude that the vertical stability profile of Venus allows GW generated on reliefs to propagate at least up to the altitude range of 52-57 km. We think that we observe the mean zonal wind deceleration due to the breaking of many GWs with small horizontal wavelengths. When GW break they transfer their momentum flux to the mean flow and they 

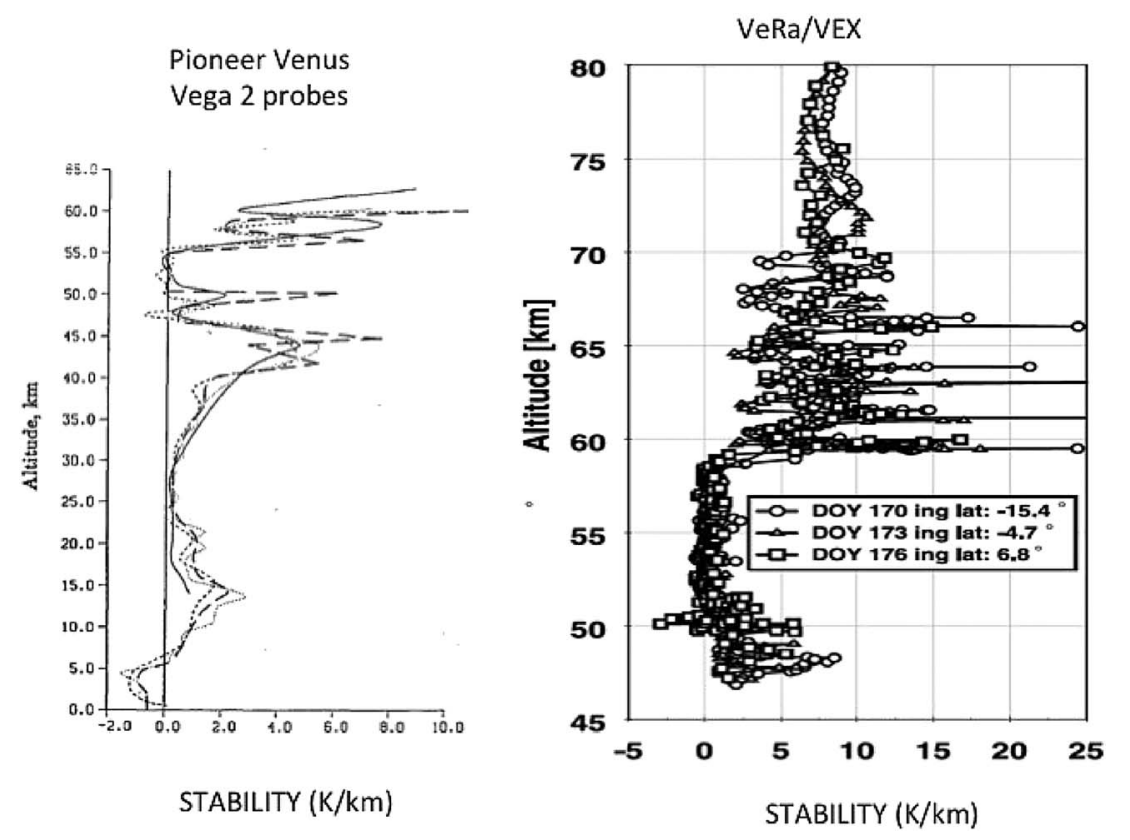

Figure 8. (left) Altitude profile of the static stability versus altitude derived from in situ temperature profiles (in units of $\mathrm{K} / \mathrm{km}$ ). Solid curve is from Pioneer Venus sounder probe taken from Seiff et al. [1980], and dashed curves are from Vega-2 lander data obtained in 1985 and discussed in Young et al. [1994]. (right) Static stability versus altitude derived from VeRa/VEX radio occultations in $\mathrm{K} / \mathrm{km}$, for three latitudes near the equator [Tellmann et al., 2009]. Note the difference of horizontal and vertical scales.

accelerate the zonal wind in the direction of their horizontal propagation relative to the mean flow. For stationary GW, it will result in a deceleration of the wind as illustrated in Figure 7. This mechanism was first proposed by Lindzen [1981] to explain the deceleration of the zonal wind observed in the Earth mesosphere and is now widely accepted in the Earth atmospheric community. In the present case of Venus, the deceleration $\mathrm{d} V / \mathrm{d} t$ that is required to explain a $17 \mathrm{~m} / \mathrm{s}$ change $\mathrm{d} V$ in $100^{\circ}$ (from longitude $200^{\circ}$ to $100^{\circ}$, Figure 3 ) is $13.2 \mathrm{~m} / \mathrm{s} /$ day, since $100^{\circ}$ of longitude corresponds to a distance of $10.5 \times 10^{3} \mathrm{~km}$ traveled in $\mathrm{d} t=1.28$ days at a mean speed of $95 \mathrm{~m} / \mathrm{s}$.

In principle gravity waves cannot propagate through an unstable layer, for instance, at 52-57 km. However, if they break and decelerate the wind at the bottom of a convective layer, the deceleration will be transferred to the whole layer by convective mixing. Then, the zonal wind at the cloud top gets modulated because of angular momentum balance between cloud top and cloud bottom.

Another condition for vertical propagation of GW is that their horizontal phase speed must be different from the mean horizontal wind. In the case of planet Venus, this condition is always fulfilled for stationary GW generated at ground level, since their phase speed is zero with respect to the ground and since the wind increases constantly with altitude up to $70 \mathrm{~km}$ (Figure 9). In the case of the Earth and as shown by Lindzen [1981], this condition is fulfilled only for certain speeds and depends on season, as is discussed further in section $A 3$.

\section{Discussion on Gravity Waves}

Gravity waves manifest themselves as quasiperiodic disturbances on the atmospheric temperature profiles or regular cloud structures. Ultraviolet images of the Venus cloud top from Mariner 10 and Pioneer Venus showed cloud features 200-1000 km in size interpreted as GW [Belton et al., 1976; Rossow et al., 1990]. VMC/Venus Express cloud top UV observations of the northern polar region have revealed frequent wave trains [Picciali et al., 2014; Titov et al., 2012], somewhat correlated with the highest terrains on Venus (Ishtar Terra and Maxwell Montes) and a higher detection rate $40-60^{\circ}$ downstream of the mountain peaks [see Picciali et al., 2014, Figure 10]. 

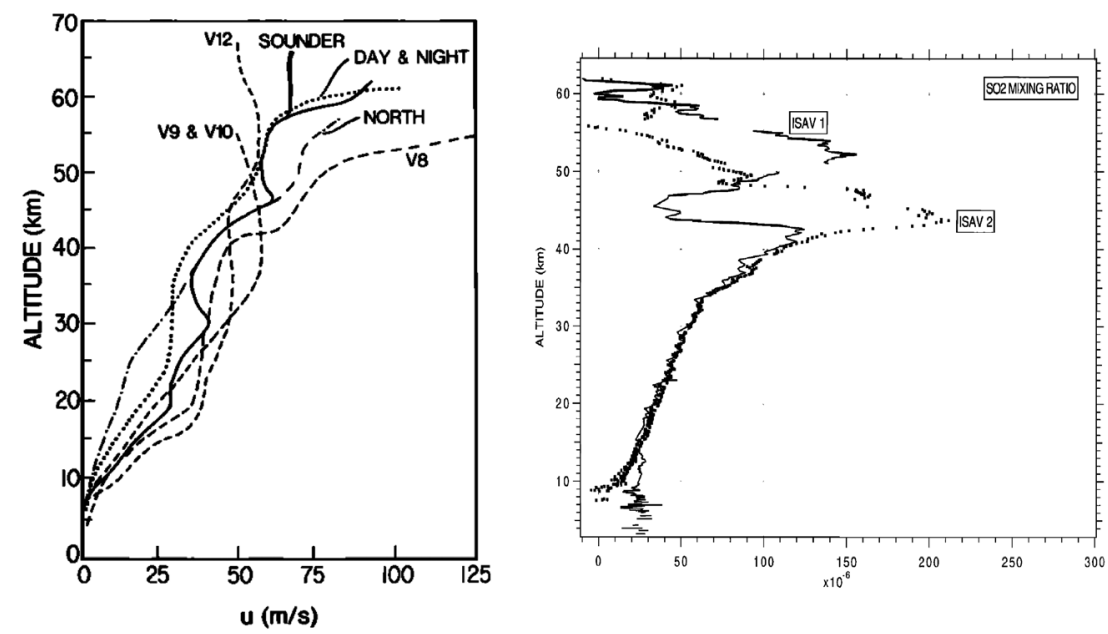

Figure 9. (left) A comparison of zonal wind velocity profiles from Pioneer Venus and Venera probes taken from Schubert et al. [1980]. (right) Vertical profile of $\mathrm{SO}_{2}$ mixing ratio (ppmv) measured within the clouds in situ from instruments ISAV-1 and ISAV-2 on descent probes of VEGA-1 and VEGA-2 in 1985 [Bertaux et al., 1996]. The decrease above the higher peak is due to captation of $\mathrm{SO}_{2}$ into droplets of $\mathrm{H}_{2} \mathrm{SO}_{4}$ and is linked to the UV absorber (see text in section 5).

Vertical profiles of wind (Figure 9, left) and temperature acquired by the four Pioneer Venus probes showed evidence for propagating gravity waves [Seiff et al., 1980; Counselman et al., 1980]. Temperature profiles retrieved from radio occultation measurements display quite often wiggles also interpreted as the signature of GW, mainly from Magellan [Hinson and Jenkins, 1995] and Venus Express spacecraft [Tellmann et al., 2009].

Magellan [Hinson and Jenkins, 1995] performed three consecutive radio occultations. The three temperature profiles were obtained on three consecutive orbits, separated by $3.26 \mathrm{~h}$, at $67^{\circ} \mathrm{N}$. It implies that the atmosphere had rotated by $\sim 18^{\circ}$ between orbits (here we revise the value of $\sim 25^{\circ}$ quoted by Hinson and Jenkins [1995] to account for the 2.8 days rotation period of the atmosphere at $67^{\circ}$ latitude [Khatuntsev et al., 2013]). Since the three temperature profiles show almost identical wiggles (the signature of GW), it shows that gravity waves are stationary relative to the Sun or to the surface. The ambiguity comes from the short time of the observations. With the findings of the present paper showing the importance of topographic elevation near equator, it is quite likely that the Magellan observed GW were linked to the surface rather than to the Sun. In addition, their Figure $3 \mathrm{~b}$ shows that the static stability for altitudes $>36 \mathrm{~km}$ (altitude range reachable by radio occultations above the critical radius for refraction) is always $>0$ and very small only in narrow regions of 1-2 km around $51-54 \mathrm{~km}$. This was not an obstacle for gravity waves which would have been generated below their observed temperature wiggles at 62-72 km.

At high northern latitudes where Ishtar Terra and Maxwell Montes are the highest terrains on Venus, the Venus Express Radio Science Experiment (VeRa) measurements show a clear enhancement of GW potential energy in the altitude range 65-80 km [Tellmann et al., 2009]; but there are no such obvious topographic enhancement near equator which are relevant to our VMC present analysis (their Figure 10). Unfortunately, owing to the particular VEX orbit configuration, there is only a very limited number of radio occultations near the equator (S. Tellmann, personal communication, 2016).

Earlier, the trajectories of the two 1985 VEGA balloons floating near $53 \mathrm{~km}$ altitude indicated that atmospheric motions are influenced by surface topography [Blamont et al., 1986]. The VEGA-1 balloon stayed at approximately $7^{\circ} \mathrm{N}$ latitude, away from high mountainous regions, and did not encounter the type of disturbances experienced by the VEGA-2 balloon: flying over Aphrodite region at $7^{\circ} \mathrm{S}$, VEGA-2 experienced enhanced vertical winds and relatively large temperature/pressure excursions, together with much larger horizontal wind variations than at any other period during either balloon flight [Preston et al., 1986; Sagdeyev et al., 1992]. The suggestion [Blamont et al., 1986; Gierasch, 1987] that gravity waves generated at the surface of Venus by horizontal flow over Aphrodite could propagate vertically up to the balloon float altitude was explored later thoroughly in the frame of linear and nonlinear theory of GW generation and propagation [Young et al., 1987, 1994].

We note that VEGA-1 and VEGA-2 balloons drifted along longitude ranges from $\sim 178$ to $73^{\circ}$ longitude, a region of decelerated wind as seen by VMC (Figure 3). Therefore, we searched if there was a difference of their 
average zonal velocity from injection to the end of their flight, 2 days later. We recomputed in Appendix A2 their average zonal velocity from the plots of Sagdeyev et al. [1992] and found $68.8 \mathrm{~m} / \mathrm{s}$ for VEGA-1 balloon flying at $8.1^{\circ} \mathrm{N}$ and $65.9 \mathrm{~m} / \mathrm{s}$ for VEGA-2 balloon flying at $7.5^{\circ} \mathrm{S}$. This is probably a more accurate ([Sagdeyev et al., 1992] analysis published in 1992, 7 years after the flight, benefiting of better trajectory reconstruction from VLBI tracking) but fully consistent with the earlier estimate of $69 \pm 1$ and $66 \pm 1 \mathrm{~m} / \mathrm{s}$, respectively, for VEGA-1 and VEGA-2 balloons [Preston et al., 1986]. The smaller velocity of VEGA-2 with respect to VEGA-1 indicates that GW are already acting on balloons floating at an altitude of $53 \mathrm{~km}$ over the most mountainous region overflown by VEGA-2 balloon (Aphrodite Terra), in contrast to VEGA-1 flying north of equator, over flat terrains and probably less GW effect.

In view of the present findings from Venus Express VMC zonal wind measurements, the presence of a similar signature of the topography in the temporal average of the zonal wind has been searched for in the latest simulations of the LMD Venus GCM. The model was described in Lebonnois et al. [2010]. It was found that even when the simulations include an orographic GW parameterization, they do not show any deceleration correlated to the topography. It is reasonable to think that the GCM does not model the atmosphere well enough to reproduce the phenomenon responsible for the correlation. Work is needed in particular to validate the parameterization of the orographic GW and its effect in the deep atmosphere in a simulation that would be more realistic than the simulations published in Lebonnois et al. [2010].

\section{UV Albedo Maps and $\mathrm{H}_{2} \mathrm{O}$ Distribution}

\subsection{The Distribution of UV Albedo and UV Absorber at Cloud Top Level}

The exact nature of the UV absorber responsible for the contrast in the UV images is still unknown. As discussed in Esposito et al. [1997], it is something in addition of $\mathrm{SO}_{2}$ and $\mathrm{SO}$ gases because these gases do not absorb longward of $320 \mathrm{~nm}$ while the UV absorber does. Among the candidates for the unknown UV absorber [Esposito et al., 1997], sulfur allotropes $\mathrm{S}_{3}, \mathrm{~S}_{4}$, and $\mathrm{S}_{8}$ have been proposed, and also, $\mathrm{S}_{2} \mathrm{O}$ and polysulfur oxides were suggested. There is however a correlation between $\mathrm{SO}_{2}$ and the UV absorber, as noted in Lee et al. [2015]. Inside the clouds, $\mathrm{SO}_{2}$ mixing ratio was measured by in situ absorption on descent probes of VEGA-1 and VEGA-2 [Bertaux et al., 1996]. It peaked at 150 ppmv at $54 \mathrm{~km}$ of altitude for VEGA-1 (Figure 9, right) and strongly decreasing above up to the measuring limit of $62 \mathrm{~km}$. The abundance of $\mathrm{SO}_{2}$ detected at cloud top level $(67 \pm 2 \mathrm{~km})$ in the scattered solar spectrum is of the order of 0.1 to 1 ppmv [Marcq et al., 2011, 2013]. Therefore, there is a strong vertical gradient of $\mathrm{SO}_{2}$ inside the clouds, showing that it is already destroyed below the cloud top level, and if the UV absorber is indeed coming from $\mathrm{SO}_{2}$, then the UV absorber must be produced inside the upper cloud, just below the cloud top level.

Perhaps even more intriguing at first glance than the variation of the zonal wind with topography is the variation of UV albedo measured by VMC at $365 \mathrm{~nm}$. In Figure 10 are compared the longitude distribution of UV albedo measured between $5^{\circ} \mathrm{S}$ and $15^{\circ} \mathrm{S}$ (top) and the wind velocity averaged in the same latitude band (curve of Figure 3, not shifted). The highest albedo at 0.52 is over elevated terrains, while the smallest albedo at 0.43 is above lower terrains, as can be inferred by comparing the UV albedo curve with topography in Figure 10 (bottom).

In Figure 11a is shown a longitude-latitude map of the UV albedo at $365 \mathrm{~nm}$ measured by VMC. It is an average of 1442 images obtained over 7.5 years from orbit 30 (May 2006) to orbit 2714 in September 2013 (more than 12 Venus years). One has to realize that the albedo map is based on an average of a very large sample of data. It is likely that a single map will not show the averaged distribution presented here. For each measurement point the UV albedo $A$ is obtained from the measured radiance $B$ and Lambert's law equation (1)

$$
A=\pi B / F_{\mathrm{s}} \cos (\mathrm{SZA})
$$

in which $F_{\mathrm{s}}$ is the solar flux at Venus and SZA is the local solar zenith angle. The map extends farther North than the wind map of Figure 6 (bottom), because there is no need of two consecutive VMC images in the case of the albedo measurement. All radiances divided by $\cos (\mathrm{SZA})$ were averaged in each $1 \times 1^{\circ}$ bin of longitude-latitude (only points with $\mathrm{SZA}<70^{\circ}$ are kept) and then multiplied by the constant $\pi / F_{\mathrm{s}}$. The number of points per bin is mapped in Figure 12. It ranges from 1000 to 5000, except near the boundaries of the observed regions.

In each bin, the average albedo and the standard deviation $\sigma$ of all points in the bin were computed, measuring the dispersion of the albedo around the mean value at a given point in longitude-latitude. The dispersion 

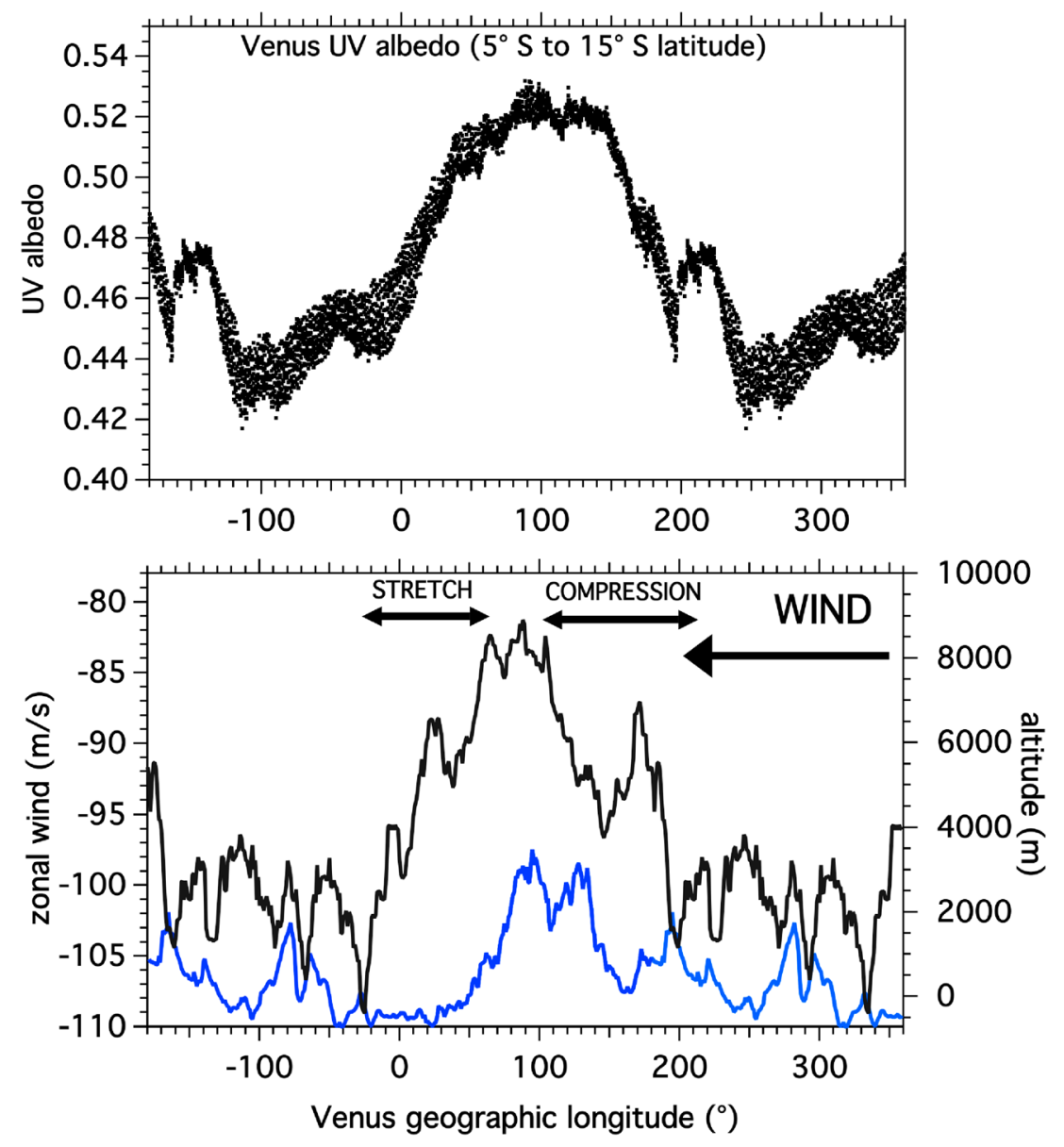

Figure 10. Latitude averages between $5^{\circ} \mathrm{S}$ and $15^{\circ} \mathrm{S}$ of (top) UV albedo and (unshifted) (bottom) zonal wind and topography. The albedo points are representing averages within $1 \times 1^{\circ}$ latitude-longitude bins. There is a strong correlation between the UV albedo curve and the wind curve, which is explained by the divergence of the zonal flow (a stretch from $60^{\circ}$ down to $-20^{\circ}$ longitude), compensated by air upwelling, increase of the UV absorber, and decrease of the UV albedo. Vice versa from $200^{\circ}$ to $110^{\circ}$, compression, air downwelling, less UV absorber, and larger UV albedo.

is a combination of natural variability of albedo above one geographical point and of the measurement error (precision); the natural variability is larger than the measurement error. The dispersion in each bin amounts from 0.1 to 0.2 in albedo units.

While the UV albedo poleward of $40^{\circ} \mathrm{S}$ is pretty uniform and higher than near the equator, a well-known fact [Limaye and Suomi, 1977] and evident on all UV images (i.e., Figure 1), there are totally unexpected structures at other places nearer the equator, both in longitude and latitude. Indeed, we would rather expect that such a long average of a large data set would smooth out in longitude the local natural variability. This longitude distribution of the UV albedo remained mysterious at first glance, but with second thoughts the underlying cause became pretty obvious.

On the one hand, in situ measurement of solar scattered UV radiation performed during the descent of Venera 14 in 1981 with a narrow band photometer centered at $370 \mathrm{~nm}$ indicated that most of the UV absorber was confined above $58 \mathrm{~km}$ but below the cloud top level [Ekonomov et al., 1984]. On the other hand, there is a meridional component of the wind away from the equator on both sides (from $\sim 0-2$ to $\sim 6 \mathrm{~m} / \mathrm{s}$ within 0 to $20^{\circ} \mathrm{S}$ latitude, Figure 13 of Khatuntsev et al. [2013], confirming earlier results). Conservation of matter indicates that if the divergence of the horizontal wind field $\mathbf{V}$ at a given level is different from 0 , it requires a convergence of the vertical motion of air to compensate. The equatorial horizontal flow divergence $\mathrm{d} V_{y} / \mathrm{d} y$ (where $y$ is ground distance along a latitude axis) is $>0$ at all longitudes and calls for upwelling air in the equatorial regions, bringing more UV absorber at cloud top. This explains why the UV albedo is, in general, lower near 

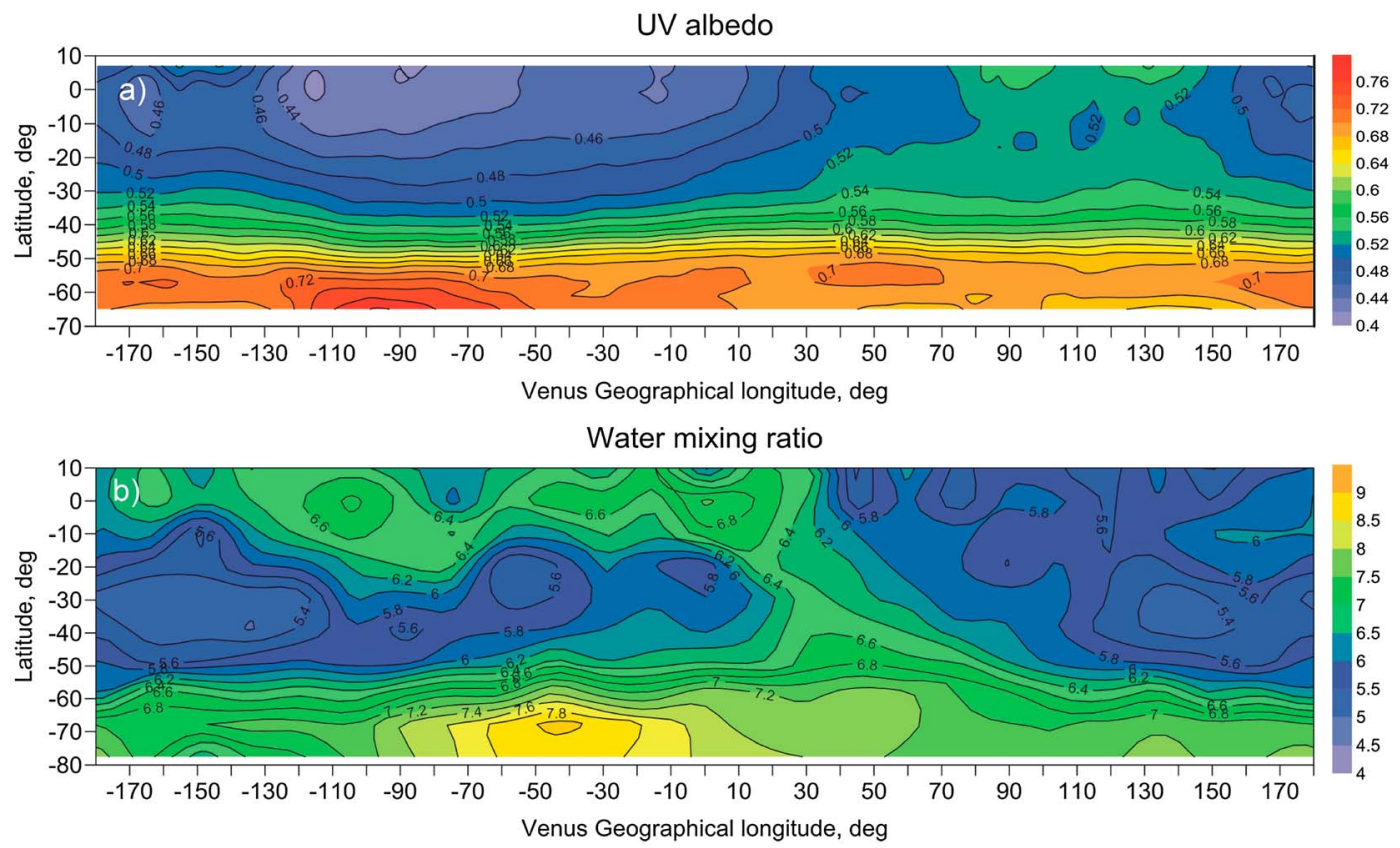

Figure 11. (a) Venus geographic map of the UV albedo. The albedo $A$ is derived from the VMC measured UV radiance ( 345 to $385 \mathrm{~nm}$ ) assuming a Lambertian behavior: $A=\pi$ radiance/[solar flux $\times \cos (\mathrm{SZA})], \mathrm{SZA}=$ solar zenith angle. $A$ was averaged in each $1 \times 1^{\circ}$ bin of longitude-latitude (only for $\mathrm{SZA}<70^{\circ}$ ). The number of points per bin ranges from 1000 to 5000 . Isocontours of UV albedo are drawn. (b) Geographic distribution at cloud top altitude of $\mathrm{H}_{2} \mathrm{O}$ mixing ratio as determined from the near-infrared spectral feature of $\mathrm{H}_{2} \mathrm{O}$ at $1.38 \mu \mathrm{m}$ detected in the solar backscattered radiation from SPICAV IR instrument on Venus Express [Fedorova et al., 2016]. Isocontours are indicated in ppmv. The data cover 8.5 years of data, 150,000 individual measurements of $\mathrm{H}_{2} \mathrm{O}$ with 1 sigma $<1$ ppmv for each point, and 50 to several hundreds of points in each longitude-latitude box.

equator than at higher latitudes. This is the basis of the classical understanding of meridional atmospheric circulation in two Hadley cells departing from the equator and going down at each pole. The UV absorber is destroyed along the path to the pole and explains the increase of UV albedo with latitude.

This effect of the horizontal flow divergence near equator is valid at all longitudes, but in addition, there is a similar and strong longitude effect where the zonal wind increases or decreases by $\pm 9 \mathrm{~m} / \mathrm{s}$ from the mean, much larger in magnitude than the meridional wind. With $x$ being the ground distance along the longitude axis, $\mathrm{d} V_{x} / \mathrm{d} x$ is positive over a certain longitude region and negative in another region. An increase of the horizontal wind magnitude $\left(\mathrm{d} V_{x} / \mathrm{d} x>0\right)$ may be visualized as a "stretching" of air which must be compen-

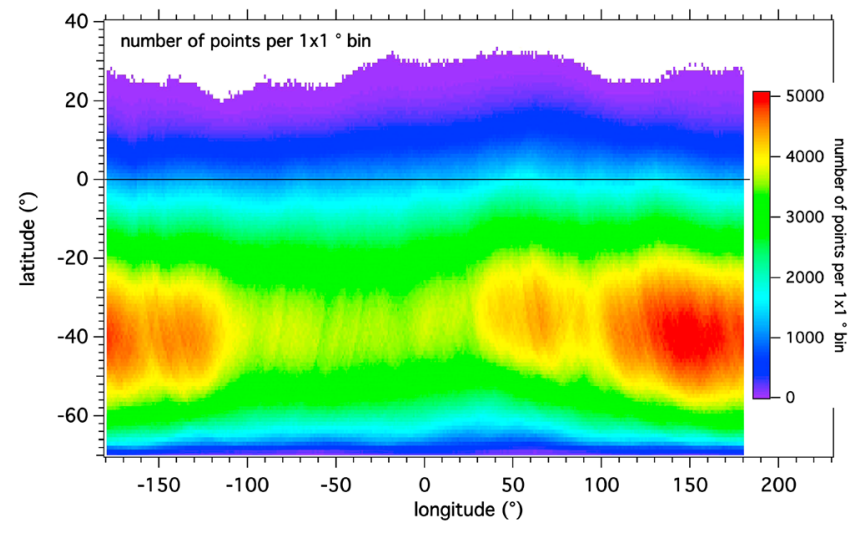

Figure 12. Number of points per $1 \times 1^{\circ}$ bin of longitude-latitude kept to compute an average albedo and its fluctuations. It ranges from $\sim 1000$ to 5000 , except near the boundaries of the observed regions. sated by a vertical flow (upwelling), while a decrease $\left(\mathrm{d} V_{x} / \mathrm{d} x<0\right)$ could be visualized as a compression calling for downwelling or less upwelling. Looking at Figure 10 and going in the wind direction, the region of increasing of the wind magnitude (from $60^{\circ}$ longitude down to $-20^{\circ}=340^{\circ}$, where $\mathrm{d} V_{x} / \mathrm{d} x>0$ ) can be visualized as a stretching of the flow. It corresponds to air upwelling, an increase of the UV absorber at cloud top and a decrease of the UV albedo. And the reverse process happens from $200^{\circ}$ to $110^{\circ}, \mathrm{d} V_{x} / \mathrm{d} x<0$, slowing down of the horizontal wind, compression, air downwelling, less UV absorber, and larger UV albedo. 


\subsection{The Distribution of Water Vapor at Cloud Top Level}

Stimulated by the present findings on geographic deceleration of the zonal wind and UV albedo, Anna Fedorova and colleagues have plotted their water vapor measurements at cloud top level in a longitudelatitude plot, as reproduced here in Figure $11 \mathrm{~b}$. They were recently compiled from 8.5 years of data acquired from the near-infrared spectral feature at $1.38 \mu \mathrm{m}$ detected in the solar backscattered radiation (from Spectroscopy for Investigation of Characteristics of the Atmosphere of Venus (SPICAV) IR instrument on Venus Express, Korablev et al. [2012]).

Figure $11 \mathrm{~b}$ shows a major effect of latitude, with more $\mathrm{H}_{2} \mathrm{O}$ poleward of $50^{\circ}$ of latitude than elsewhere in both hemispheres (north hemisphere not shown here). This is related to the $\mathrm{H}_{2} \mathrm{O}$ mixing ratio vertical profile decreasing with altitude inside the clouds, combined with the fact that clouds at latitudes $>60^{\circ}$ are at lower altitude by $\sim 6 \mathrm{~km}$ than in equatorial and middle-latitude regions. More $\mathrm{H}_{2} \mathrm{O}$ come into view when the clouds are lower.

Indeed, the cloud droplets of Venus are made of condensed $\mathrm{H}_{2} \mathrm{SO}_{4}$ (solution of sulfuric acid). While the volume mixing ratio of $\mathrm{H}_{2} \mathrm{O}$ is $\sim 30 \mathrm{ppmv}$ in the bulk and lower atmosphere [Marcq et al., 2008; Bézard et al., 2011; Fedorova et al., 2015], there is only 6 ppmv at cloud top level (Figure 11b, from SPICAV IR data analyzed in Fedorova et al. [2016]) indicating that most of $\mathrm{H}_{2} \mathrm{O}$ is captured in the clouds by $\mathrm{SO}_{2}$ oxidized to $\mathrm{SO}_{3}$ and forming $\mathrm{H}_{2} \mathrm{SO}_{4}$ (it remains only 1-2 ppmv of $\mathrm{H}_{2} \mathrm{O}$ above the clouds as measured by solar occultations with Solar Occultation in the InfraRed (SOIR) instrument on Venus Express, Fedorova et al. [2008]). This is a well-established fact, well understood, and well modeled. The most recent model [Krasnopolsky, 2015, Figure 8] shows 25 ppmv at $48 \mathrm{~km}, 14 \mathrm{ppmv}$ at $60 \mathrm{~km}$, and $4 \mathrm{ppmv}$ at $65 \mathrm{~km}$. Therefore, there is inside the clouds a strong negative vertical gradient $\mathrm{d} \mu\left(\mathrm{H}_{2} \mathrm{O}\right) / \mathrm{d} z$ of water vapor mixing ratio $\mu\left(\mathrm{H}_{2} \mathrm{O}\right)$ (decrease with increasing altitude), which in such conditions is an ideal dynamical tracer of vertical motions of air: the larger is the upwelling, the more $\mathrm{H}_{2} \mathrm{O}$ is brought to the level where it can be detected from space (cloud top level). Focusing now our attention to the equatorial region from -20 to $+10^{\circ}$ latitude, we see on the $\mathrm{H}_{2} \mathrm{O}$ map of Figure $11 \mathrm{~b}$ that the $\mathrm{H}_{2} \mathrm{O}$ mixing ratio is larger than $6 \mathrm{ppmv}$ in the range from $-160^{\circ}$ to $+30^{\circ}$ longitude and smaller than 6 ppmv at other longitudes. This $\mathrm{H}_{2} \mathrm{O}$ feature is statistically solid (8.5 years of data), and it demonstrates an increased upwelling of air in this particular $-160^{\circ}$ to $+30^{\circ}$ longitude region (at least on the dayside where observations are made).

The longitude-latitude maps of $\mathrm{H}_{2} \mathrm{O}$ (Figure 11b) and UV albedo (Figure 11a) show a striking anticorrelation in the low-latitude regions, at least down to $20^{\circ} \mathrm{S}$ of latitude. The longitude region of low UV albedo at equator coincides with the region of increased water vapor both in longitude and latitude, as shown by the isocontours at 6.4 ppmv. It confirms that the UV absorber is present in upwelling regions (revealed by water vapor), and therefore, it must be produced below the cloud top level. It had been already suggested that UV bright regions are associated with downwelling [Del Genio and Rossow, 1990; Esposito and Travis, 1982], and here we demonstrate that UV dark regions are associated to an upwelling regime with the UV absorber produced within the upper cloud.

From the UV alone, it is not possible to decide if air is descending or ascending without making a hypothesis about the vertical distribution of the UV absorber. The case of water vapor, where we know that the vertical gradient $\mathrm{d} \mu\left(\mathrm{H}_{2} \mathrm{O}\right) / \mathrm{d} z$ of mixing ratio $\mu\left(\mathrm{H}_{2} \mathrm{O}\right)$ is negative, discriminates the case and calls for upwelling in regions richer in $\mathrm{H}_{2} \mathrm{O}$, imposing also that the UV absorber is present below the cloud top level (as indicated by Venera 14 results) and brought at cloud top by ascending air.

A thorough analysis of VMC UV albedos compared to radiative transfer model [Molaverdikhani et al., 2012] showed that VMC observations could be fitted by two different vertical distributions of the UV absorber: either a well-mixed species, located mostly at altitudes above the bottom of the upper cloud deck ( $150 \mathrm{mbar}$ ) and below the cloud top, or as a thin layer of pure absorber at the top of upper clouds $24 \pm 5 \mathrm{mbar}$ or 70-72 km (which is above the cloud top level). This uncertainty illustrates the difficulty (likely an impossibility) to locate exactly in altitude the UV absorber on the sole ground of radiative transfer modeling compared to observations. Our analysis is rather based on two other lines of arguments: one is the correlation of $\mathrm{SO}_{2}$ with the UV absorber, and we know that the major part of $\mathrm{SO}_{2}$ is below the cloud top; the other is the observed upwelling of $\mathrm{H}_{2} \mathrm{O}$, correlated with a lower UV albedo, which demonstrates that the UV absorber is carried to cloud top by upwelling. This upwelling is just the consequence of the divergence of the wind flow, meridional, or zonal. For Molaverdikhani et al. [2012], their favorite location for the UV absorber is, without being 
certain, the well-mixed model within the upper cloud. Our analysis fully concurs with this scheme, and there is no need for the high-altitude thin layer above the cloud top level.

In summary, $\mathrm{H}_{2} \mathrm{O}$ and UV albedo at cloud top in the low-latitude regions are only indirectly connected to topography below, through the influence of GW on the horizontal gradient of the zonal wind.

We may speculate on the existence of a zonally oriented circulation cell in which we would see the upper part at cloud top level. $\mathrm{SO}_{2}$ above the clouds is also monitored by VEX [Marcq et al., 2013], but the long-term variations spanning one order of magnitude make the available data set too sparse to detect a significant correlation with Venusian topography or longitude. Careful reanalysis of a larger data set may alleviate these difficulties in the near future.

\section{Conclusions}

From the analysis of a large data set of individual wind measurements collected with VMCNEX, we have shown that the zonal winds near cloud top level $(\sim 67 \pm 2 \mathrm{~km})$ show a geographic pattern which is correlated with surface topography. The present longitude analysis of VMC zonal winds suggests indeed that topography is decelerating the zonal wind, and we are proposing a mechanism based on stationary gravity waves generated at ground level, propagating upward until a breaking altitude, where they deposit their momentum and decelerate the winds. Such a gravity wave mechanism is known to operate in the Earth atmosphere, as proposed by Lindzen [1981] to explain the seasonal variation of mesospheric vertical wind profiles. The deceleration observed in the atmosphere of Venus is a fact that should be accounted for when superrotation mechanisms are discussed. Current GCM models which can reproduce superrotation do not reproduce yet this effect.

This analysis shows that the zonal wind at cloud top level correlates with surface topography. The temporal trend (increase of the wind velocity from 2006 to 2010) reported by Khatuntsev et al. [2013] is now understood as an aliasing artifact linked to the combination of the longitude-latitude distribution of the wind speed and the measurements sampling near the geographic longitude of the subsolar point, which drifted slowly from a longitude of slow zonal wind to a longitude of stronger wind. Similarly to the apparent wind speed trend, it is likely that the temporal trend of UV contrast and albedo reported by Lee et al. [2015] is also apparent, exactly for the same reasons as the wind artifact.

Other atmospheric parameters may also be mapped as a function of geography. We have presented the geographic distribution of UV albedo and found a conspicuous longitude structure, totally unexpected. We have shown that near the equatorial region, there is a striking similarity between the UV albedo distribution and $\mathrm{H}_{2} \mathrm{O}$ distribution at cloud top level as established by SPICAV IR data Fedorova et al., 2016]. We provided an explanation, with upwelling of more humid air compensating for the zonal wind longitude gradient for mass conservation. In some sense, there is an atmospheric fountain located downstream of Aphrodite Terra, where the wind is reaccelerating after a zone of deceleration. The low albedo associated with high $\mathrm{H}_{2} \mathrm{O}$ near equator demonstrates that the UV absorber is produced below the cloud top and is brought by upwelling together with $\mathrm{H}_{2} \mathrm{O}$. In this explanation, the UV albedo and $\mathrm{H}_{2} \mathrm{O}$ variations are a secondary effect of the influence of stationary GW influencing the zonal wind magnitude.

These new findings are totally justifying the remarkable intuition of Young et al. [1994] who wrote: "...large topographic slopes are ubiquitous over the surface of Venus and hence topographic wave forcing may be an important momentum source for the global circulation at cloud levels and above." This intuition is supported by the present analysis of VMC zonal winds. The deceleration of the zonal wind by stationary gravity generated on high-altitude reliefs is a fact that should be accounted for when superrotation mechanisms are discussed.

With the successful capture in orbit of Japanese Akatsuki mission and its good imaging capabilities, it is hoped that all the findings presented in this paper will be confirmed and studied in more detail by our Japanese colleagues.

\section{Appendix A: Additional Aspects}

\section{A1. The Length of Venus Solar Day and Frequency Signature of Periodogram}

In Table A1 is indicated the length of the day for both planets Earth and Venus (in units of hours and terrestrial days). One must distinguish the length of the sidereal day (the time separating the passage above a given 
Table A1. Length of Day and Year on Earth and Venus

\begin{tabular}{lcc} 
& Earth & Venus \\
\hline Length of year (days) & 365.24 & 224.7 \\
Length of sidereal day (mountain facing a star) & $23 \mathrm{~h} 56 \mathrm{~min}$ & 243 days \\
Length of solar day (mountain facing the sun) & $24 \mathrm{~h}$ & 117 days \\
\hline
\end{tabular}

geographic meridian of a given star) from the length of the solar day (the time separating the passage above a given geographic meridian of the sun). It is often quoted in the literature that on Venus the length of the day is longer than the year. This statement is quite misleading. It is true for the sidereal day (243 terrestrial days, longer than the length of the year which is 224.7 terrestrial days); it is not true for the solar day (117 days), and the solar day is a much more important controlling factor than the sidereal day for any planet. It can be noted that on Earth the solar day is longer than the sidereal day (by $4 \mathrm{mn}$ ), while on Venus it is the contrary: the solar day is shorter than the sidereal day. This is because of the retrograde rotation of the planet. A particular longitude of Venus will see the sun at the local meridian every 117 days.

Let us assume that one Venus parameter (for example, the zonal wind velocity) would depend on the Venus geographic longitude and assume dayside observations only as illustrated in Figure A1. The sampling window will be centered on, or not far from, the subsolar point geographic longitude, which moves by $360^{\circ}$ in 117 days. Therefore, the following theorem may be formulated: if a parameter measured on the dayside depends on the geographic longitude, then a time series of such measurements will show a period at 117 days, regardless of other geometric conditions of observations (like the fact that the orbit of Venus Express is fixed in inertial space.)

Reciprocally, if a period of 117 days is found on a parameter measured on the dayside, it is likely that it depends on the geographic longitude, which can be checked by plotting the parameter as a function of longitude. In their study of VMC zonal wind from VMC/VEX, Khatuntsev et al. [2013] found indeed in the periodogram of the zonal wind a peak at 117 days that triggered our attention.

\section{A2. The Trajectories of VEGA-1 and VEGA-2 Balloons}

During the soviet missions VEGA-1 and VEGA-2, two identical balloons were deployed in the atmosphere of Venus and stay afloat at an altitude of $\sim 53 \mathrm{~km}$ for $\sim 2$ days, VEGA-1 at $8.1^{\circ} \mathrm{N}$ and VEGA-2 at $7.5^{\circ} \mathrm{S}$ [Blamont et al., 1986]). From Table 1 of Sagdeyev et al. [1992] giving the time and longitudes of both balloons, we may compute the average zonal velocity from injection to the final transmission. Taking into account the radius of Venus at $53 \mathrm{~km}$ of altitude, we find $68.8 \mathrm{~m} / \mathrm{s}$ for VEGA- 1 balloon flying at $8.1^{\circ} \mathrm{N}$ and $65.9 \mathrm{~m} / \mathrm{s}$ for VEGA-2 balloon flying at $7.5^{\circ} \mathrm{S}$. This is probably more accurate (analysis published in 1992, 7 years after the flight) but fully consistent with the earlier estimate of Preston et al. [1986] of $69 \pm 1$ and $66 \pm 1 \mathrm{~m} / \mathrm{s}$, respectively, for VEGA-1 and VEGA-2 balloons. The longitudes of the two balloons changed from 176.9 to $68.8^{\circ}$ for Balloon 1 and from 179.8 to $76.3^{\circ}$ for Balloon 2. Therefore, this Balloon 2 was in the geographical region of
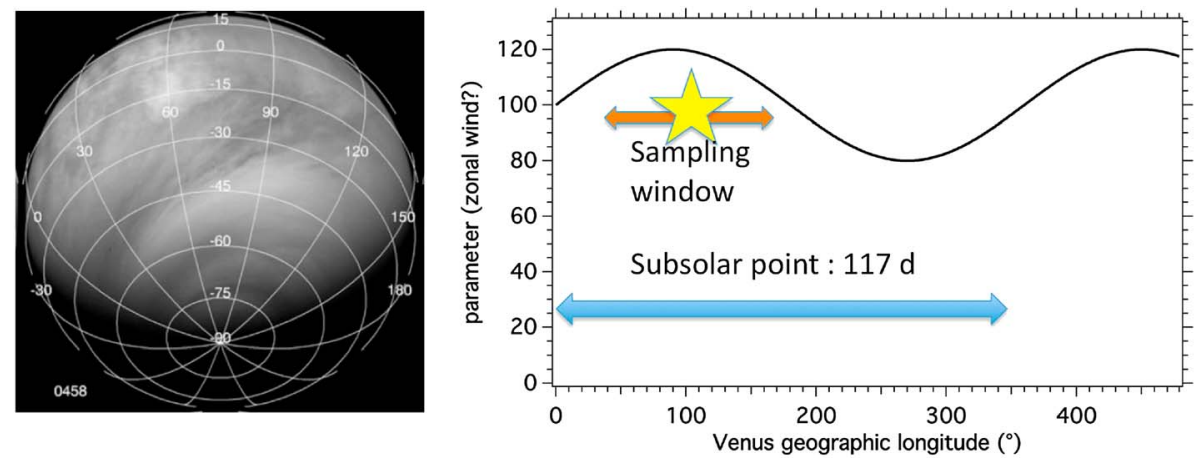

Figure A1. (left) A typical image of VMCNEX used to make zonal wind measurements. Regions near the terminator are avoided. (right) Illustration of the theorem. The sine wave would represent a parameter that would depend on the geographic longitude. The red arrow, centered on the subsolar longitude, moves by $360^{\circ}$ in 117 days, producing a corresponding frequency peak in the periodogram of a time series of the parameter. The theorem would be valid also for nightside-only measurements. 
Table A2. Longitude of VEGA-1 Balloon B1 and of VEGA-2 Balloon B2 at Start and End of Mission and Average Velocity ${ }^{\mathrm{a}}$

\begin{tabular}{|c|c|c|c|c|c|}
\hline Balloon 1 & Time (UT) h:min:s & Latitude (deg) & Longitude (deg) & Zonal Distance Traveled (km) & Mean Velocity $(\mathrm{m} / \mathrm{s})$ \\
\hline B-1 injection & 02:06:10 & $8.1^{\circ} \mathrm{N}$ & 176.9 & 0 & \\
\hline B-1 final transmission & $48: 38$ & $8.1^{\circ} \mathrm{N}$ & 68.8 & 11,523 & 68.8 \\
\hline B-2 injection & 02:06:04 & $7.5^{\circ} \mathrm{S}$ & 179.8 & 0 & \\
\hline B-2 final transmission & 48:38:01 & $7.5^{\circ} \mathrm{S}$ & 76.3 & 11,033 & 65.9 \\
\hline
\end{tabular}

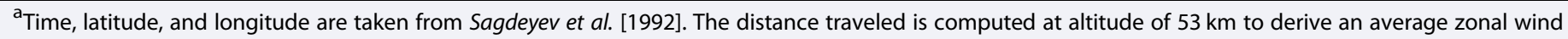
velocity.

decelerated wind as mapped by VMC (Figure $2 \mathrm{~b}$ ) and its lower mean zonal velocity ( $-4 \%$ compared to Balloon 1, which latitude is over less mountainous regions) is consistent with our VMC findings. Since we have no good coverage at $8^{\circ} \mathrm{N}$ for VMC winds, we may assume that the zonal wind at $8^{\circ} \mathrm{N}$ is the same as over nonmountainous regions south of the equator where there is good VMC wind coverage (Figure 6, bottom). From Figure 3 we compute that the average zonal wind over the longitude range of Balloon 2 (76.3 to $\left.179.8^{\circ}\right)$ is $-89.1 \mathrm{~m} / \mathrm{s}$, while it is $-101 \mathrm{~m} / \mathrm{s}$ in the longitude region $\left(200-360^{\circ}\right)$ that we consider as unperturbed. This is a deceleration of $-12 \%$, therefore higher at $67 \mathrm{~km}$ than at $53 \mathrm{~km}$.

Still, Vega balloons show that there is already an effect at $53 \mathrm{~km}$, in the lower part of a low stability region as measured by VERA radio occultations measurements [Tellmann et al., 2009, Figure 3]. It shows that GW are already beginning to break at $53 \mathrm{~km}$ but that their decelerating effect is even higher at higher altitudes. Therefore, they probably break also at altitudes higher than $53 \mathrm{~km}$ (Table A2).

\section{A3. Propagation of Stationary Gravity Waves in the Atmosphere of the Earth}

As an exercise of comparative planetology, it is interesting to compare the conditions of vertical propagation of gravity waves on planets Earth and Venus. One condition for vertical propagation of GW is that their horizontal phase speed must be different from the mean horizontal wind. In the case of planet Venus, this condition is always fulfilled for stationary GW generated at ground level, since their phase speed is zero with respect to the ground and since the wind increases constantly with altitude up to $70 \mathrm{~km}$ (Figure 9). In the case of the Earth and as shown by Lindzen [1981], this condition is fulfilled only for certain speeds and depends on season. Figure A2 illustrates the propagation of gravity waves in the Northern Hemisphere of the Earth atmosphere. In winter winds are blowing from west in both the troposphere and the middle atmosphere (stratosphere/mesosphere, from 12 to $90 \mathrm{~km}$ ). Stationary and westward traveling gravity waves generated at low altitude can propagate up to the upper mesosphere with a constant horizontal phase speed and an increasing amplitude due to the exponential decrease of the atmospheric density.

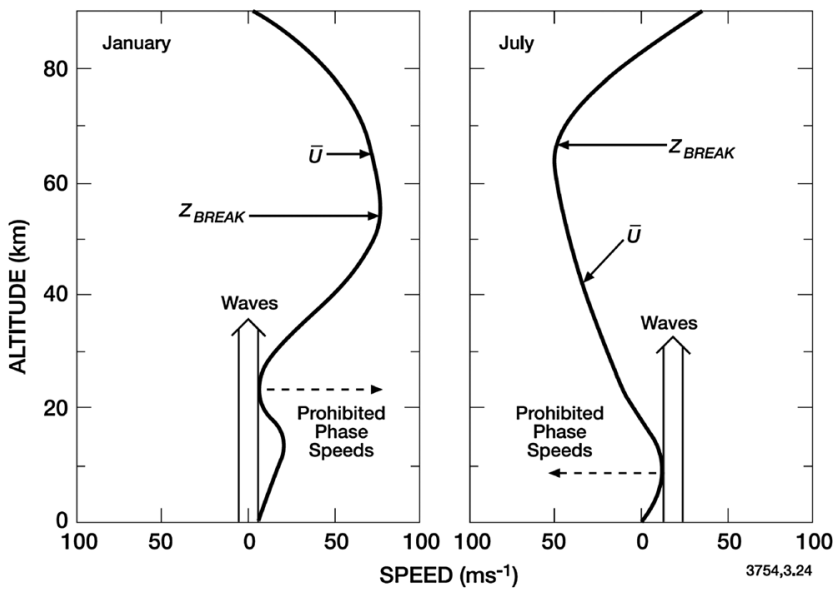

Figure A2. Approximate altitude profiles of the mean zonal winds in (left) winter and (right) summer of the Earth Northern Hemisphere. The permitted phase speeds for the propagation of gravity waves and their breaking levels are also shown. Reproduced from Brasseur and Solomon [2005, p.76] and adapted from Lindzen [1981].
When they reach a level where their phase speed is close to the mean zonal wind or their amplitude large enough to create a shear instability, they break and they transfer their momentum flux to the mean flow, creating an acceleration in the direction of their propagation relative to the mean wind. This explains the closure of the mesospheric jet around $90 \mathrm{~km}$. In summer a similar process occurs but in the opposite direction. Only gravity waves with an eastward phase speed can propagate up to the upper mesosphere, creating a closure of the mesospheric easterly jet. The mechanism of deceleration of the zonal wind by the breaking of gravity waves can operate in all planetary atmospheres and in particular in the Venus atmosphere. 


\section{Acknowledgments}

Venus Express is an ESA mission. We wish to acknowledge the efforts of engineers in the science teams at ESAC and ESOC for the successful operation of this unique Venus mission and in particular Hakan Svedhem, Dima Titov and Colin Wilson. This research was supported by CNES and CNRS at LATMOS. VMC images are publicly available in the ESA PSA archive at $\mathrm{ftp}: / /$ psa.esac.esa.int/pub/mirror/VENUSEXPRESS/VMC/.

\section{References}

Belton, M. J. S., G. R. Smith, G. Schubert, and A. D. Del Genio (1976), Cloud patterns, waves and convection in the Venus atmosphere, J. Atmos. Sci., 33, 1394-1417.

Bertaux, J. L., T. Widemann, A. Hauchecorne, V. I. Moroz, and A. P. Ekonomov (1996), Vega-1 and Vega-2 entry probes: An investigation of local UV absorption (220-400 nm) in the atmosphere of Venus (SO2, aerosols, cloud structure), J. Geophys. Res., 101, 12,709-12,745, doi:10.1029/96JE00466.

Bézard, B., A. Fedorova, J.-L. Bertaux, A. Rodin, and O. Korablev (2011), The 1.10- and 1.18- $\mu \mathrm{m}$ nightside windows of Venus observed by SPICAV-IR aboard Venus Express, Icarus, 216(1), 173-183, doi:10.1016/j.icarus.2011.08.025.

Blamont, J. E., et al. (1986), Implications of the VEGA balloon results for Venus atmospheric dynamics, Science, 231, $1422-1425$.

Boyer, C., and H. Camichel (1961), Observations photographiques de la planète Vénus, Ann. Astrophys., 24, 531-535.

Brasseur G., and S. Solomon (2005), Aeronomy of the Middle Atmosphere, Chemistry and Physics of the Stratosphere and Mesosphere, 3rd revis. and enlarged ed., 644 pp., Springer, Dordrecht, Netherlands.

Counselman, C. C., III, S. A. Gourevitch, R. W. King, G. B. Loriot, and E. S. Ginsberg (1980), Zonal and meridional circulation of the lower atmosphere of Venus determined by radio interferometry, J. Geophys. Res., 85, 8026-8030, doi:10.1029/JA085iA13p08026.

Del Genio, A. D., and W. B. Rossow (1990), Planetary-scale waves and the cyclic nature of cloud top dynamics on Venus, J. Atmos. Sci., 47, 293-318.

Ekonomov, A. P., V. I. Moroz, B. E. Moshkin, V. I. Gnedykh, Y. M. Golovin, and A. V. Grigoriev (1984), Scattered UV solar radiation within the clouds of Venus, Nature, 307, 345-347.

Esposito, L. W., and L. D. Travis (1982), Polarization studies of the Venus UV contrasts: Cloud height and haze variability, Icarus, 51, 374-390.

Esposito, L. W., J. L. Bertaux, V. Krasnopolsky, V. I. Moroz, and L. L. Zasova (1997), Chemistry of lower atmosphere and clouds, in Venus II, edited by S. W. Bougher, D. M. Hunten, and R. J. Philipps, pp. 415-458, Univ. of Ariz. Press, Tucson.

Fedorova, A., et al. (2008), HDO and $\mathrm{H}_{2} \mathrm{O}$ vertical distributions and isotopic ratio in the Venus mesosphere by Solar Occultation at Infrared spectrometer on board Venus Express, J. Geophys. Res., 113, E00B22, doi:10.1029/2008JE003146.

Fedorova, A., B. Bézard, J.-L. Bertaux, O. Korablev, and C. Wilson (2015), The $\mathrm{CO}_{2}$ continuum absorption in the 1.10- and 1.18- $\mu \mathrm{m}$ windows on Venus from Maxwell Montes transits by SPICAV IR onboard Venus Express, Planet. Space Sci., 113, 66, doi:10.1016/j.pss.2014.08.010.

Fedorova, A., E. Marcq, M. Luginin, O. Korablev, J.-L. Bertaux, and F. Montmessin (2016), Variations of the water vapor and the cloud haze in the Venus' mesosphere from SPICAV/VEx observations, Icarus, 275, 143-162.

Gierasch, P. J. (1987), Waves in the atmosphere of Venus, Nature, 328, 510-512.

Hinson, D. P., and J. M. Jenkins (1995), Magellan radio occultation measurements of atmospheric waves on Venus, Icarus, $114,310-327$.

Khatuntsev, I. V., M. V. Patsaeva, D. V. Titov, N. I. Ignatiev, A. V. Turin, S. S. Limaye, W. J. Markiewicz, M. Almeida, T. Roatsch, and R. Moissl (2013), Cloud level winds from the Venus Express Monitoring Camera imaging, Icarus, 226, 140-158.

Korablev, O., et al. (2012), SPICAV IR acousto-optic spectrometer experiment on Venus Express, Planet. Space Sci., 65(1), 38-57.

Krasnopolsky, V. A. (2015), Vertical profiles of $\mathrm{H}_{2} \mathrm{O}, \mathrm{H}_{2} \mathrm{SO}_{4}$, and sulfuric acid concentration at 45-75 km on Venus, Icarus, 252, $327-333$.

Lebonnois, S., F. Hourdin, V. Eymet, A. Crespin, R. Fournier, and F. Forget (2010), Superrotation of Venus' atmosphere analyzed with a full general circulation model, J. Geophys. Res., 115, E06006, doi:10.1029/2009JE003458.

Lee, Y. J., T. Imamura, S. E. Schröder, and E. Marcq (2015), Long-term variations of the UV contrast on Venus observed by the Venus Monitoring Camera on board Venus Express, Icarus, 253, 1-15.

Limaye, S. S., and V. E. Suomi (1977), A normalized view of Venus, J. Atmos. Sci., 34, 205-215.

Lindzen, R. S. (1981), Turbulence and stress owing to gravity wave and tidal breakdown, J. Geophys. Res., 86, 9707-9714, doi:10.1029/ JC086iC10p09707.

Marcq, E., B. Bézard, P. Drossart, G. Piccioni, J.-M. Reess, and F. Henry (2008), A latitudinal survey of $\mathrm{CO}, \mathrm{OCS}_{2} \mathrm{H}_{2} \mathrm{O}$, and $\mathrm{SO}_{2}$ in the lower atmosphere of Venus: Spectroscopic studies using VIRTIS-H, J. Geophys. Res., 113, E00B07, doi:10.1029/2008JE003074.

Marcq, E., D. Belyaev, F. Montmessin, A. Fedorova, J.-L. Bertaux, A. C. Vandaele, and E. Neefs (2011), An investigation of the $\mathrm{SO}_{2}$ content of the Venusian mesosphere using SPICAV-UV in nadir mode, Icarus, 211(1), 58-69, doi:10.1016/j.icarus.2010.08.021.

Marcq, E., J.-L. Bertaux, F. Montmessin, and D. Belyaev (2013), Variations of sulphur dioxide at the cloud top of Venus's dynamic atmosphere, Nat. Geosci., 6, 25-28.

Markiewicz, W. J., et al. (2007a), Venus monitoring camera for Venus express, Planet. Space Sci., 55(12), 1701-1711, doi:10.1016/j.pss.2007.01.004

Markiewicz, W. J., D. V. Titov, S. S. Limaye, H. U. Keller, N. Ignatiev, R. Jaumann, N. Thomas, H. Michalik, R. Moissl, and P. Russo (2007b), Morphology and dynamics of the upper cloud layer of Venus, Nature, 450(7170), 633-636.

Moissl, R., et al. (2009), Cloud top winds from tracking UV features in Venus Monitoring Camera images, J. Geophys. Res., 114, E00B31, doi:10.1029/2008JE003117.

Molaverdikhani, K., K. McGouldrick, and L. W. Esposito (2012), The abundance and vertical distribution of the unknown ultraviolet absorber in the Venusian atmosphere from analysis of Venus Monitoring Camera images, Icarus, 217, 648-660.

Patsaeva, M. V., I. V. Khatuntsev, D. V. Patsaev, D. V. Titov, N. I. Ignatiev, W. J. Markiewicz, and A. V. Rodin (2015), The relationship between mesoscale circulation and cloud morphology at the upper cloud level of Venus from VMC/Venus Express, Planet. Space Sci., 113, 100-108, doi:10.1016/j.pss.2015.01.013.

Picciali, A., D. V. Titov, A. Sanchez-Lavega, J. Peralta, O. Shalygina, W. J. Markiewicz, and H. Svedhem (2014), High latitude gravity waves at the Venus cloud tops as observed by the Venus Monitoring Camera on board Venus Express, Icarus, 227, $94-111$.

Preston, R., et al. (1986), Determination of Venus winds by ground-based radio tracking of the VEGA balloons, Science, 231, 1414-1416.

Rossow, W. B., A. T. Del Genio, and T. Eichler (1990), Cloud-tracked winds from Pioneer Venus OCPP images, J. Atmos. Sci., 47, $2053-2084$.

Sagdeyev, R. Z., et al. (1992), Differential VLBI measurements of the Venus atmosphere dynamics by balloons: VEGA project, Astron. Astrophys., 254, 387-392.

Schubert, G., et al. (1980), Structure and circulation of the Venus atmosphere, J. Geophys. Res., 85, 8007-8025, doi:10.1029/JA085iA13p08007

Seiff, A., D. B. Kirk, R. E. Young, R. C. Blanchard, J. T. Findlay, G. M. Kelly, and S. C. Sommer (1980), Measurements of thermal structure and thermal contrasts in the atmosphere of Venus and related dynamical observations: Results from the four Pioneer Venus Probes, J. Geophys. Res., 85, 7903-7933, doi:10.1029/JA085iA13p07903.

Tellmann, S., M. Pätzold, B. Häusler, M. K. Bird, and G. L. Tyler (2009), Structure of the Venus neutral atmosphere as observed by the Radio Science experiment VeRa on Venus Express, J. Geophys. Res., 114, E00B36, doi:10.1029/2008JE003204.

Titov, D. V., et al. (2012), Morphology of the cloud tops as observed by the Venus Express monitoring camera, Icarus, $217($ I2), $682-701$.

Young, R. E., R. L. Walterscheid, G. Schubert, A. Seiff, V. M. Linkin, and A. N. Lipatov (1987), Characteristics of gravity waves generated by surface topography on Venus: Comparison with the VEGA balloon results, J. Atmos. Sci., 44(18), 2628-2639.

Young, R. E., R. L. Walterscheid, G. Schubert, L. Pfister, H. Houben, and D. L. Bindschadler (1994), Characteristics of finite amplitude stationary gravity waves in the atmosphere of Venus, J. Atmos. Sci., 51(13), 1857-1875. 